\title{
How a sex pheromone might act at a concentration below $10^{-16} \mathrm{M}$
}

\section{Manfred Sumper, Elke Berg, Stephan Wenzl and Klaus Godl}

Lehrstuhl Biochemie I, Universität Regensburg, 8400 Regensburg, Germany

Communicated by W.Tanner

The sex-inducing pheromone of Volvox carteri is a glycoprotein that triggers development of males and females at a concentration below $10^{-16} \mathrm{M}$. Evidence is presented for the existence of a novel mechanism of signal amplification operating within the extracellular matrix of this multicellular organism. A family of $70 \mathrm{kDa}$ matrix glycoproteins denoted pherophorins bear a C-terminal domain being homologous to the sex-inducing pheromone. Under the influence of the pheromone, this domain is liberated by highly specific proteolysis.

Key words: extracellular matrix/pheromone/sexual inducer/ signal amplification/Volvox

\section{Introduction}

The sexual pheromone (sexual inducer) of the multicellular green flagellate Volvox carteri is a glycoprotein synthesized and released by sperm cells (Starr, 1969, 1970; Starr and Jaenicke, 1974; Gilles et al., 1981; Tschochner et al., 1987; Mages et al., 1988). It is one of the most potent biological effector molecules known: it exhibits full effectiveness at $6 \times 10^{-17} \mathrm{M}$ and a single sexual male produces enough inducer to convert many millions of asexually growing males and females to the sexual pathway (Starr, 1970; Gilles et al., 1984).

Asexual spheroids of both the male and female strains exhibit 2000-4000 biflagellate somatic cells (similar to Chlamydomonas in their morphology) that are arranged in a monolayer at the surface of a hollow sphere (Starr, 1969). Only 16 much larger asexual reproductive cells ('gonidia') lie just below the somatic cells. The cells are held together by a glycoprotein-rich extracellular matrix (ECM) (for review, see Kirk et al., 1986). The ECM sheath shows considerable structural organization in that it exhibits clearly visible boundaries towards the interior of the spheroid as well as honeycomb-like structures around each cell (Ertl et al., 1989).

The sex-inducing pheromone causes a gonidium to cleave in a different pattern to initiate development of a sexual organism (Starr, 1970). In the asexual cycle of both females and males the first unequal cleavage occurs in 16 cells of the 32-cell embryo to generate 16 (large) gonidial initials. In pheromone-treated gonidia of females, however, the first unequal cleavage is delayed one cycle, resulting in 32 (or more) reproductive initials which finally differentiate to egg cells (Figure 1B). In contrast, in sexually induced gonidia of males, the first unequal cleavage takes place at the 256-cell embryo and affects all cells, so that a 1:1 ratio of somatic and reproductive ('androgonidia') initials is produced (Figure 1C). The androgonidia ultimately develop into packets of sperm cells.

The ultimate target of pheromone action obviously is the gonidium of the asexual organism. Hence it has generally been assumed that the gonidium is also the site of initial inducer action. However, the exquisite sensitivity of the inducing system calls for a potent signal amplification and can hardly be explained in terms of conventional receptor/ effector-mediated interactions. The first biochemical response detected so far is a structural modification within the extracellular matrix (Wenzl and Sumper, 1982, 1986; Gilles et al., 1983). In particular, the earliest response, detectable a few minutes after the application of the pheromone is the synthesis of an extracellular sulfated glycoprotein with an apparent molecular mass of $70 \mathrm{kDa}$ (SG 70). Remarkably, this glycoprotein is synthesized by the somatic cells of the organism (Wenzl and Sumper, 1986).

In this paper, we describe the isolation of this extracellular matrix glycoprotein and demonstrate the existence of a gene family for SG 70 glycoproteins. The deduced amino acid sequence reveals a highly unexpected result. The $\mathrm{C}$-terminal third ( $\sim 190$ amino acid residues in length) is homologous to the sex-inducing pheromone and during sexual induction, this domain is liberated by specific proteolysis from the parent molecule. In the light of this finding, a mechanism of signal amplification in this extremely sensitive pheromone system is proposed and supported experimentally.

\section{Results}

\section{Induction of SG 70 synthesis}

The earliest biochemical response to the application of the sexual pheromone is the synthesis of a tyrosine sulfatecontaining glycoprotein that was denoted SG 70 (Wenzl and Sumper, 1986). SG 70 is synthesized exclusively by somatic cells, rather than by the reproductive cells, the ultimate recipients of the pheromone's message. Shortly after its production, SG 70 becomes deposited in an insoluble form within the extracellular matrix. An important hint for an understanding of its biological function is provided by a pulse-chase labelling experiment (Figure 2). After the application of the sexual pheromone, synchronously developing Volvox spheroids were pulse labelled with $\left[{ }^{35} \mathrm{~S}\right]$ sulfate $(60 \mathrm{~min})$, conditions which allow a high incorporation of radioactivity into the SG 70 glycoprotein. Even after its deposition within the extracellular matrix (a process that takes $\sim 60-90 \mathrm{~min}$ ), SG 70 turned out to be an unstable molecule being proteolytically degraded in a highly specific manner. With a half life of $\sim 6 \mathrm{~h}$, SG 70 decays quantitatively into two defined cleavage products of apparent molecular masses 42 and $30 \mathrm{kDa}$ (Figure 2). These cleavage products were found to be stable for at least $24 \mathrm{~h}$. 


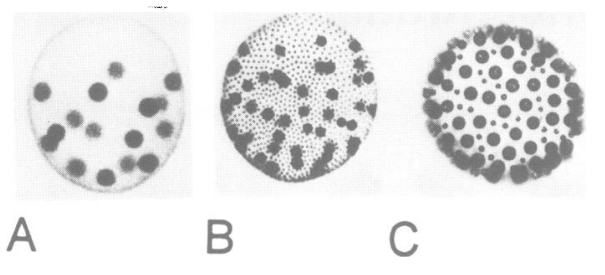

Fig. 1. Asexual and sexually induced Volvox spheroids. (A) the asexual organism (male or female); (B) sexually induced female; (C) sexually induced male.

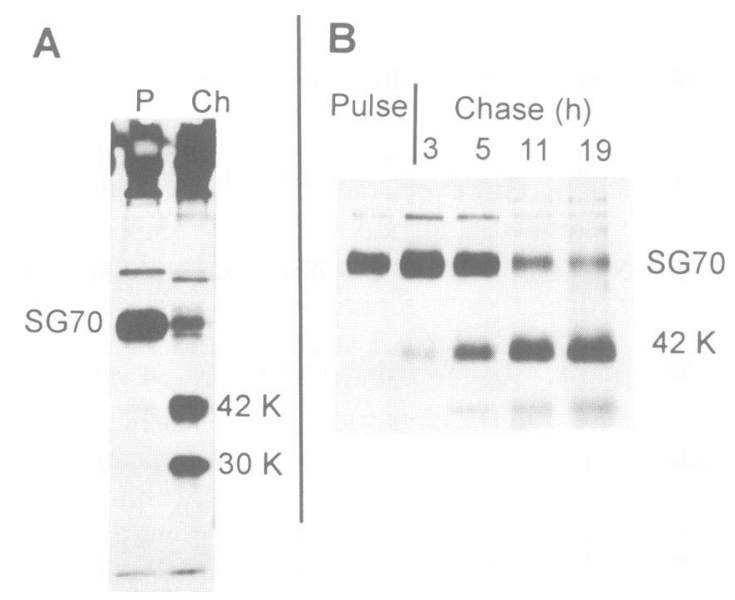

Fig. 2. Specific cleavage of SG 70 in vivo. Fluorograms of SDS-polyacrylamide gels loaded with extracts from Volvox spheroids pulse- or pulse-chase-labelled with $\left[{ }^{35}\right.$ S] sulfate. (A) Pheromone was added to a Volvox population $(\sim 0.1 \mathrm{pM})$ followed by the addition of radioactive sulfate. After a pulse labelling period of $60 \mathrm{~min}$, an aliquot was removed and the EDTA extract from 50 Volvox ghosts (Materials and methods) was applied to $10 \%$ SDS-PAGE (P). After a chase of $18 \mathrm{~h}$, another aliquot of the population was analysed in exactly the same way (Ch). (B) Kinetics of SG 70 cleavage in vivo. Pulse-chase labelling as described for (A), except that Volvox ghosts were solubilized by HF treatment (Materials and methods) for a quantitative recovery of the cleavage products.

\section{Purification of SG 70}

In a previous article, we have shown that newly synthesized SG 70 becomes converted into a highly insoluble structural element of the ECM, remaining insoluble even in 1\% SDS solution at $95^{\circ} \mathrm{C}$ (Wenzl and Sumper, 1986). This property was used to purify SG 70. Sexually induced Volvox spheroids were boiled for $5 \mathrm{~min}$ in $1 \%$ SDS containing $0.5 \mathrm{M} \mathrm{NaCl}$. This rigorous treatment solubilizes most intracellular proteins but leaves intact the insoluble extracellular matrix structure. Thus colourless Volvox 'ghosts' are obtained. Extraction of these ghosts with $100 \mathrm{mM}$ EDTA in the presence of $1 \%$ detergents like Triton X-100 or Mega-9 highly selectively removes SG 70 as well as the $42 \mathrm{kDa}$ cleavage product. Final purification was achieved by preparative SDS-PAGE. Alternatively, Volvox 'ghosts' are quantitatively solubilized by treatment with anhydrous hydrogen fluoride at $0^{\circ} \mathrm{C}$, a procedure that selectively deglycosylates glycoproteins but does not cleave polypeptides (Mort and Lamport, 1977). After HF treatment of ghosts, only two main polypeptides are detectable on SDS-PAGE. One of these polypeptides was identified as the previously described extracellular matrix glycoprotein SSG 185 (Ertl et al., 1989), whereas the remaining main polypeptide was derived from SG 70 .

\section{Protein chemical studies}

The purified SG 70 polypeptide was readily digested by proteinases like trypsin, chymotrypsin or proteinase Lys-C. The resulting peptide mixtures were separated by reversed phase $\mathrm{C}_{18}$ HPLC. The materials of well-separated peaks were directly subjected to amino acid sequence analysis on an automated gas phase sequencer. All amino acid sequences determined are underlined in Figure 4. A comparison of all amino acid sequences obtained revealed an important fact. Two peptides turned out to be closely related, indicating the existence either of at least two SG 70 genes or of repeating sequences within the same gene product. To avoid any complication introduced by the possibility of mixing information from different genes, we only used the sequence information derived from one and the same peptide for the subsequent cloning procedure.

\section{Generation of CDNA probes by PCR}

The amino acid sequence information from the tryptic peptide KIEINVNQVCDVFGNVV-ATLNGVPTK (peptide 1) was used to synthesize the sense oligonucleotide primer AAGATYGAGATYAA corresponding to amino acids $1-5$. The antisense primer GTNGGNACKCCGTT was derived from amino acid positions $22-26$ of the same peptide. The latter primer served to reverse transcribe mRNA from sexually induced (30 min) Volvox spheroids. The resulting cDNA was amplified by the PCR in the presence of both the sense and antisense primers. Thirty cycles of amplification produced a cDNA fragment of $80 \mathrm{bp}$ in length that was cloned by blunt-end ligation into pUC18. Sequencing this insert revealed an open reading frame matching the amino acid sequence of peptide 1. Exactly the same strategy was applied to produce an $83 \mathrm{bp}$ fragment encoding the amino acid positions 3-30 of the peptide (denoted peptide 2) KTIADSWGATGTDTLKVNLNWNLLQANGGK. The oligonucleotides ATYGCKGAYAGCTGGGG and TTKCCKCCGTTKGCYTG served as sense and antisense primers, respectively. The resulting cDNA fragments were then used as highly specific probes to screen a Volvox cDNA library.

\section{Cloning of the SG 70 genes}

A cDNA library in the $\lambda$ gt 11 vector was constructed using poly(A) ${ }^{+}$RNA from sexually induced Volvox spheroids. Each of the PCR-generated probes was used separately to screen the library $\left(2 \times 10^{5}\right.$ phages per screening). In both cases a few positive clones could be identified. The corresponding inserts were subcloned into pUC18 and sequenced. As shown schematically in Figure 3, the peptide 1-derived probe detected a $0.9 \mathrm{~kb}$ cDNA fragment that terminated at its 3'-end at an EcoRI site located within the coding region of the gene. The sequences of the remaining 5 '- and $3^{\prime}$-stretches were established by the RACE-PCR technique (Frohman et al., 1988). Figure 3 schematically summarizes the strategy applied to collect the complete cDNA sequence information. The probe derived from peptide 2 allowed the identification of a recombinant $\lambda$ gt 11 clone carrying a $1.8 \mathrm{~kb}$ insert. Transcription of this insert had been initiated at the poly(A) tail of the corresponding mRNA without producing, however, a full-length transcript. Therefore the remaining sequence information were again collected by the RACE-PCR technology (Figure 3). The nucleotide sequence analysis of the complete cDNAs confirmed that peptides 1 and 2 are indeed encoded by 


\section{Pherophorin I}

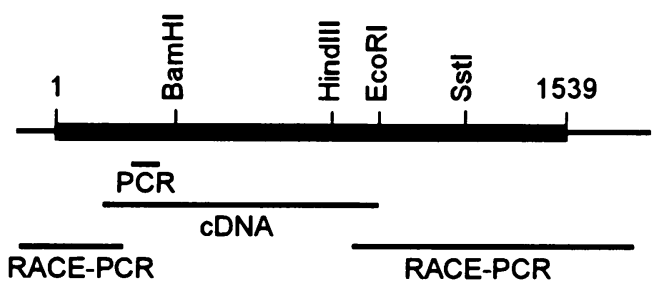

\section{Pherophorin II}

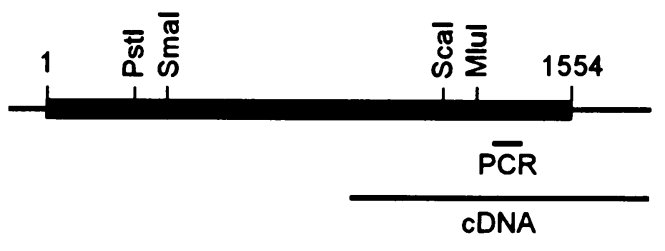

RACE-PCR

Fig. 3. Strategy applied to collect the complete nucleotide sequence of pherophorin I and pherophorin II cDNAs. Amino acid sequence information from a peptide was used to synthesize sense and antisense primers for PCR-amplification of a short cDNA fragment. A cDNA library was probed with this fragment. Completion of the cDNA sequences was achieved by RACE-PCR.

different but related genes. The deduced amino acid sequences (Figure 4) share $31 \%$ identity and exhibit $73 \%$ similarity. Common to both polypeptides is a stretch of proline residues around amino acid position 170, indicating the existence of two well separated domains consisting of $\sim 170$ and 300 amino acid residues, respectively. Both polypeptides contain potential $\mathrm{N}$-glycosylation sites ( 7 and 8 , respectively).

\section{SG 70 shares homology with the sexual inducer glycoprotein}

The result of a homology search was highly unexpected: the C-terminally located domains of both SG 70 polypeptide chains share $30 \%$ identity ( $71 \%$ similarity) with the sexinducing pheromone glycoprotein. This is documented in Figure 5. The pheromone glycoprotein that is synthesized and secreted into the medium by sperm cells consists of a polypeptide with 197 amino acid residues (Mages et al., 1988). The region of homology within the SG 70 molecules covers nearly the total length of the pheromone polypeptide chain. Particularly, all of the cysteine residues of the pheromone remain conserved in the SG 70 domains indicating conservation of the three-dimensional structure. Since both the SG 70 molecules carry a homologue of the pheromone as a C-terminally located domain we would like to denote these novel extracellular matrix glycoproteins as pherophorins I and II.

\section{Transcriptional control of pherophorin synthesis}

PCR was used to determine whether synthesis of both pherophorins is influenced by the presence of the sexual pheromone at the level of transcription. RNA was extracted from 10 asexual spheroids ( $1 \mathrm{~h}$ after release from the mother spheroid). Spheroids from the same population were treated with the sexual pheromone and after 20 min, RNA was again

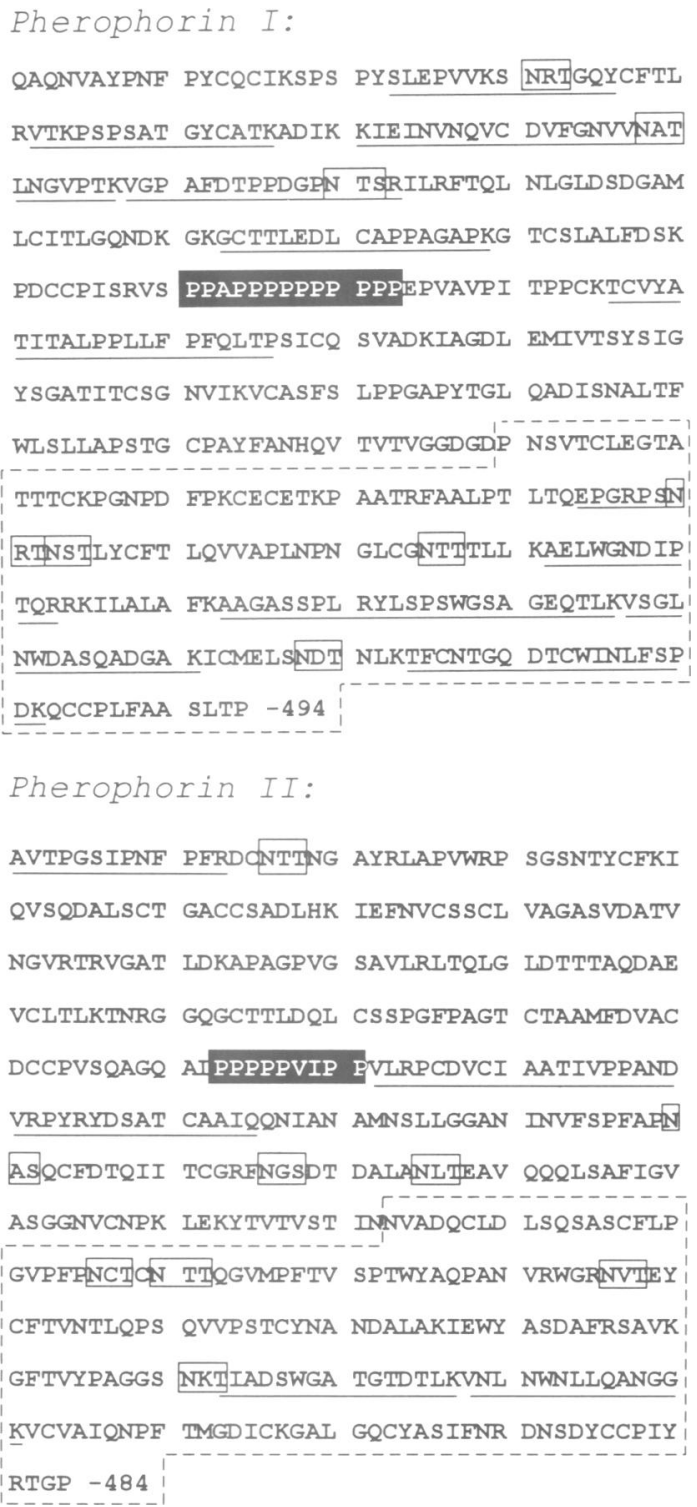

Fig. 4. Deduced amino acid sequences of pherophorins I and II. A polyproline stretch around amino acid position 170 is denoted in white letters. Amino acid sequences confirmed from isolated peptides are underlined. Potential N-glycosylation sites are boxed. The broken line marks the C-terminal part of the polypeptide found to be homologous to the sex-inducing pheromone.

extracted from 10 Volvox spheroids. Two antisense oligonucleotides specific for pherophorins I and II, respectively were applied simultaneously to reverse transcribe the RNA populations. Subsequent PCR amplification of pherophorin I and II cDNA fragments yielded the results documented in Figure 6. Pherophorin I mRNA levels remain essentially unaffected by the pheromone treatment. In sharp contrast, transcription of the pherophorin II gene is strongly induced in the presence of the sexual pheromone. Thus, pherophorin I appears to be constitutively expressed, whereas pherophorin II synthesis is strongly stimulated in response to the application of the sexual pheromone.

Site of pherophorin II cleavage

Originally, the $42 \mathrm{kDa}$ cleavage product was found to be derived from a pherophorin species produced under the 


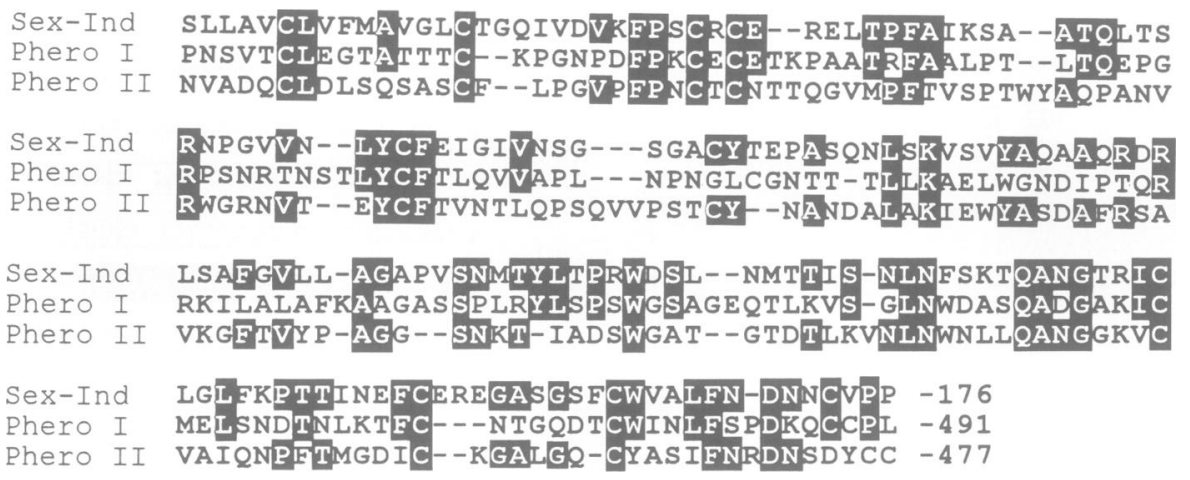

Fig. 5. Alignment and comparison of the sex-inducing pheromone (Sex-Ind) with the C-terminally located domains of pherophorins I and II. Only identities are indicated. A comparison of the pheromone and the pherophorins indicates $30 \%$ identity and $71 \%$ similarity.

influence of the sexual pheromone. Therefore, the PCR results presented so far suggest that the $42 \mathrm{kDa}$ cleavage product may be derived only from pherophorin II. The purification procedure for pherophorins described above also allows the purification of the $42 \mathrm{kDa}$ cleavage product. Automated Edman degradation of the purified fragment showed that its N-terminal sequence was VLRPCDVCIAATI. This sequence is indeed derived from pherophorin II, matching amino acid positions 182-194. Thus, the cleavage site is exactly adjacent to the polyproline stretch supposed to operate as a linker between two protein domains. Out of four tryptic peptides isolated from the $42 \mathrm{kDa}$ cleavage fragment, none was derived from pherophorin I, substantiating the idea that only pherophorin II is proteolytically processed. It is interesting to note that pherophorin I exhibits an insertion of seven amino acid residues (EPVAVPI) at the position corresponding to the pherophorin II cleavage site and this might cause the resistance of pherophorin I to proteolytic cleavage.

\section{Pherophorin II synthesis in sterile mutants}

In the literature, a number of mutants are described which are affected in the sexual induction process (Zeikus and Starr, 1980). Sterile mutants are particularly easy to detect, since they continue asexual growth in the presence of the sexinducing pheromone. If expression and proteolytic cleavage of pherophorin II are essential processes in the sexual induction pathway, at least some of these sterile mutants should be affected in these particular steps. For this reason, the expression of pherophorin I and II genes in sterile mutants was studied either in the absence or in the presence of the sexual pheromone. Again, the PCR based technology mentioned above was used for this intention. A total of three independently isolated sterile mutants were investigated (ster gone 12 from the culture collection of algae at Austin and another two sterile mutants which had spontaneously originated in our laboratory). The results of this PCR experiment are documented in Figure 7. All of the sterile mutants investigated are indeed unable to increase the transcription rate of the pherophorin II gene in response to the application of the pheromone, whereas the pherophorin I gene remains constitutively expressed as it is found in the wild type strain.

\section{Discussion}

The sex-inducing pheromone of V.carteri is one of the most powerful regulatory proteins known: it triggers the biological

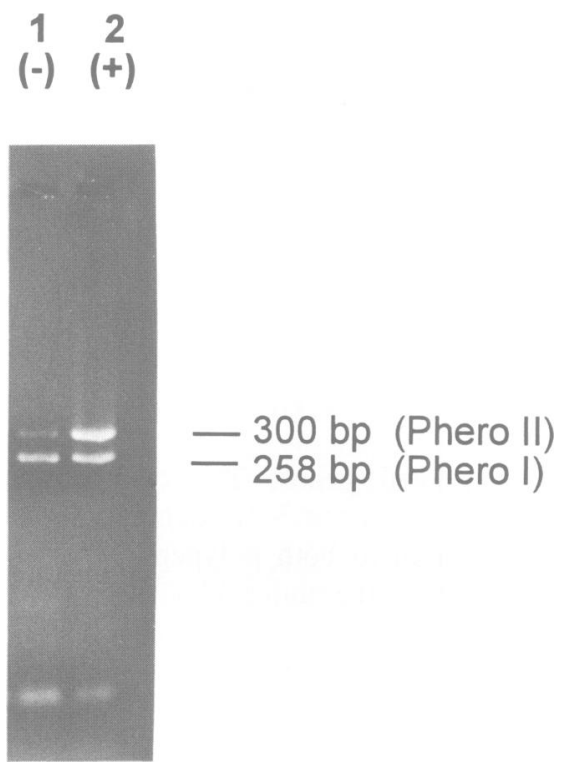

Fig. 6. Transcriptional control of pherophorin II synthesis. RNA was extracted from 10 asexual Volvox spheroids (-) or from 10 sexually induced spheroids $(+)$. After reverse transcription in the presence of both a pherophorin I- and a pherophorin II-specific antisense oligonucleotide, a 258 bp fragment derived from pherophorin I and a $300 \mathrm{bp}$ fragment derived from pherophorin II were amplified by PCR. For details see Materials and methods.

response at a concentration below $10^{-16} \mathrm{M}$. This exquisite sensitivity allows quantitative conversion to the sexual pathway of a Volvox population living in a pond or even in a small lake. For this reason, attempts to elucidate the mechanism of this signal transduction have constituted one of the intensive areas of Volvox research for more than two decades. However, none of the models proposed so far have been verified experimentally and the mechanism remained highly enigmatic. In particular, a role of cAMP claimed many times as an extracellularly acting second messenger (Gilles et al., 1985) could be excluded experimentally (Wenzl and Sumper, 1986, 1987). Any mechanism proposed for the sexual induction process has to explain at least the three following paradoxes observed for the action of the pheromone. (i) Despite its extreme sensitivity, a rather prolonged exposure to the pheromone is required to trigger sexual induction (Gilles et al., 1984). Independent of the pheromone concentration applied, an exposure of at least $6 \mathrm{~h}$ to the pheromone is required before uncleaved gonidia of a Volvox spheroid become committed to initiating sexual 

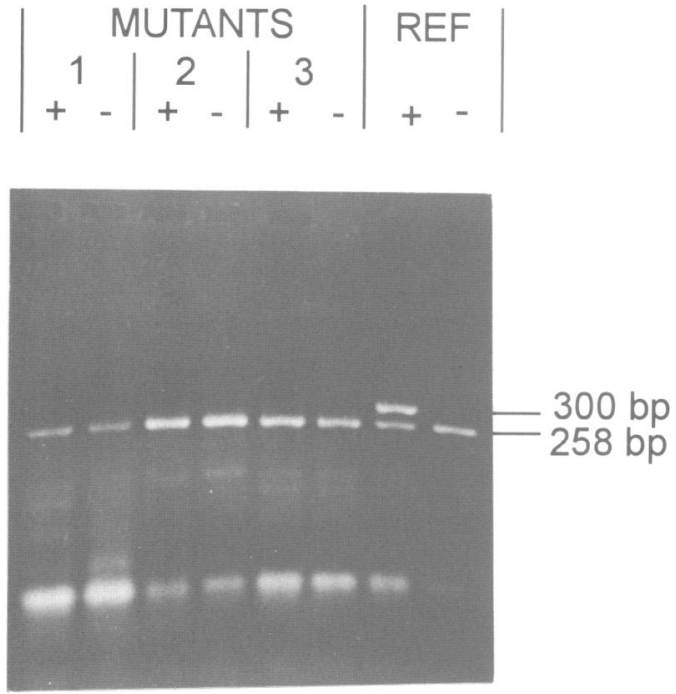

Fig. 7. Pherophorin I and II transcription in sterile Volvox mutants. RNA was extracted from 10 spheroids incubated in the absence $(-)$ or presence $(+)$ of the sex-inducing pheromone. The following strains were tested: wild type HK 10 (REF) and the sterile mutants gone 12 (1), HK 10-N2 (2) and HK 10-N3 (3). Reverse transcription and PCR amplification of pherophorin I and II mRNA were performed as described in the legend to Figure 6.

development. These observations suggest that some slowly accumulated product of pheromone action must reach a critical threshold level.

(ii) Obviously, the ultimate target of the pheromone's signal is the uncleaved reproductive cell (gonidium) that will eventually divide to produce either an asexual or a sexual offspring. However, all of the early biochemical events that have been detected in response to the pheromone take place in either the somatic cells or the extracellular matrix. This is all the more puzzling since gonidia can actually be induced by the pheromone in the absence of either somatic cells or ECM (Wenzl and Sumper, 1986).

(iii) Isolated gonidia, however, require much higher concentrations (at least two orders of magnitude) of pheromone in order to enter the sexual pathway. This had been interpreted to indicate the existence of a signal amplification system provided by the somatic cells and the surrounding ECM (Wenzl and Sumper, 1986).

The discovery of the pherophorins and the characterization of their biochemical properties offers a new approach to solve the puzzles mentioned above. The answer emerging for the question 'how might a pheromone trigger a biological response at or below $10^{-16} \mathrm{M}^{\prime}$, is as follows.

(i) The highly negatively charged ECM per se has the property to bind in a non-specific manner positively charged molecules, including the positively charged pheromone molecule (Gilles et al., 1984). This leads to an accumulation of pheromone within the ECM (a 300-fold accumulation was estimated experimentally). If this electrostatic binding is restricted to the surface of the spheroid, the transition from three- to two-dimensional diffusion would further increase the probability of encountering a somatic cell.

(ii) A Volvox spheroid contains $\sim 4000$ somatic cells at the surface and only 16 gonidia lying much deeper. Therefore, the somatic cell population has a probability at least two orders of magnitude higher than the gonidia of encountering a pheromone molecule or another signal molecule produced within the ECM in response to the pheromone. It is the somatic cell population that synthesizes pherophorin II in response to the application of the pheromone. This glycoprotein is secreted and deposited within the ECM and within a few hours, a $42 \mathrm{kDa}$ domain that is a homologue of the sex-inducing pheromone is proteolytically cleaved from pherophorin II. If this cleavage product also has the biological property to induce a gonidium, the massive production of pherophorin II would raise the inducing principle within the ECM by orders of magnitude. Subsequently, a classical receptor/effectormediated interaction would be sufficient to trigger the gonidium.

A number of experimental observations support the idea that the $42 \mathrm{kDa}$ cleavage product of pherophorin II indeed has sex-inducing activity. In particular, all sterile mutants tested lack the ability to produce this fragment. Unfortunately, we were not able to demonstrate biological activity for a corresponding polypeptide expressed in Escherichia coli by recombinant DNA technology. However, authentic pherophorin II is a highly glycosylated and tyrosine-sulfated polypeptide (Wenzl and Sumper, 1986) and thus, the recombinant product may indeed be expected to lack biological activity.

Interestingly, pherophorin I which also bears a pheromonehomologous domain is constitutively expressed and is not cleaved under any circumstances. This glycoprotein represents one of the most abundant components of the insoluble fraction of the extracellular matrix. It is tempting to speculate that the highly potent sex-inducing pheromone is evolutionarily derived as a cleavage product from a member of the pherophorin family that originally served a structural function within the ECM of multicellular green algae.

\section{Materials and methods}

\section{Culture conditions}

Volvox carteri $f$. nagariensis, strains HK 10 (female), 69-1b (male) and the sterile mutants ster gone 12 and ster gone 78 were obtained from the culture collection of algae at the University of Texas (Dr R.C.Starr). Synchronous cultures were grown in Volvox medium (Provasoli and Pintner, 1959) at $28^{\circ} \mathrm{C}$ in an $8 \mathrm{~h}$ dark $/ 16 \mathrm{~h}$ light (10 000 lux) cycle (Starr and Jaenicke, 1974).

\section{Pulse labelling of pherophorins}

Pulse labelling with $\left.{ }^{35} \mathrm{~S}\right]$ sulfate was performed as described by Wenzl and Sumper (1986).

\section{Purification of pherophorins}

Sexually induced Volvox spheroids (HK 10) from three 201 cultures containing gonidia initiating embryogenesis were harvested by filtration through a nylon screen. The spheroids were sliced by forcing them through a $0.6 \mathrm{~mm}$ hypodermic needle. The suspension of spheroid fragments $(500$ ml) was adjusted to $1 \% \mathrm{SDS}$ and $0.5 \mathrm{M} \mathrm{NaCl}$ and incubated at $95^{\circ} \mathrm{C}$ for 5 min. The ruptured Volvox 'ghosts' were collected by centrifugation $(16000 \mathrm{~g}, 10 \mathrm{~min})$ and washed four times with water. This material was used for the isolation of intact pherophorins as well as deglycosylated pherophorins and the $42 \mathrm{kDa}$ cleavage product. For an easy detection of SG 70, a small amount of pulse-labelled ghosts $\left(\left[{ }^{35} \mathrm{~S}\right]\right.$ sulfate) were added at this stage.

Intact pherophorin was extracted from the 'ghosts' with $250 \mathrm{ml} 1 \%$ Mega-9 detergent (Sigma) and $100 \mathrm{mM}$ EDTA pH 8.0 at $65^{\circ} \mathrm{C}$ for $20 \mathrm{~min}$. This extract contains the pherophorins as the main protein component, but is still contaminated by large quantities of polysaccharides. These were removed by a phenol extraction $\left(80 \mathrm{ml}\right.$ phenol at $\left.65^{\circ} \mathrm{C}, 10 \mathrm{~min}\right)$. Addition of $3 \mathrm{vol}$ of acetone $\left(-20^{\circ} \mathrm{C}\right)$ to the phenol phase precipitated the pherophorins, which were collected by centrifugation. Final purification was achieved by SDS-PAGE ( $10 \%$ gel). The pherophorins were localized by staining with 
$\mathrm{KCl}$ (Hager and Burgess, 1980), and eluted from the gel by diffusion. This procedure yielded $\sim 100 \mu \mathrm{g}$ pherophorin.

Deglycosylated pherophorins as well as the C-terminal cleavage product were isolated as follows. The suspension of 'ghosts' was dried (eight aliquots) in vacuo. The dry material was dissolved in $1 \mathrm{ml}$ anhydrous hydrogen fluoride and incubated at $0^{\circ} \mathrm{C}$ for $90 \mathrm{~min}$. $\mathrm{HF}$ was removed in a stream of nitrogen and the remaining material was dissolved in SDS sample buffer and immediately adjusted to $\mathrm{pH} 8$ with $1 \mathrm{M}$ Tris base. Final purification was achieved by SDS-PAGE (12\% gel) as described above.

\section{Proteolytic digestion and separation of peptides}

$100 \mu \mathrm{g}$ pherophorin were dissolved in $400 \mu \mathrm{l} 50 \mathrm{mM}$ Tris $-\mathrm{HCl}(\mathrm{pH} \mathrm{8.0)}$ and digested with $2.5 \mu \mathrm{g}$ of endoproteinase Lys C (Boehringer, Mannheim) at $37^{\circ} \mathrm{C}$. After $4 \mathrm{~h}$, an additional $2.5 \mu \mathrm{g}$ of endoproteinase Lys $\mathrm{C}$ was added and digestion was continued for $6 \mathrm{~h}$. Peptides were separated by reversed phase HPLC on a Lichrospher $100 \mathrm{CH} 18 / 2(10 \mu \mathrm{m})$ column (E.Merck, Darmstadt, Germany) as described by Ertl et al. (1989).

\section{Generation of CDNA probes by PCR}

RNA and poly(A)+ RNA was extracted from sexually induced Volvox spheroids as described by Kirk and Kirk (1985). Reverse transcription was performed in a final volume of $20 \mu \mathrm{l}$ containing the following reagents: $50 \mathrm{mM}$ Tris $-\mathrm{HCl}$ (pH 8.3), $40 \mathrm{mM} \mathrm{KCl}, 6 \mathrm{mM} \mathrm{MgCl}, 1 \mathrm{mM}$ dithiothreitol, $20 \mathrm{U}$ RNAguard (Pharmacia), 200 pmol degenerate antisense oligonucleotide, $1 \mathrm{mM}$ each dNTP, $250 \mathrm{ng}$ poly(A) ${ }^{+}$RNA, and $200 \mathrm{U}$ of MoMuLV reverse transcriptase. Incubation was at $42^{\circ} \mathrm{C}$ for $60 \mathrm{~min}$. After addition of $80 \mu \mathrm{l}$ of $1 \times$ PCR buffer containing 500 pmol of degenerate sense oligonucleotide and $2.5 \mathrm{U}$ of Taq polymerase thermal cycling (PerkinElmer cycler 9600 ) was initiated ( 30 cycles: denaturation at $94^{\circ} \mathrm{C}$ for 45 $\mathrm{s}$, annealing at $50^{\circ} \mathrm{C}$ for $30 \mathrm{~s}$ and extending at $72^{\circ} \mathrm{C}$ for $15 \mathrm{~s}$ ). The resulting $80 \mathrm{bp}$ (or $83 \mathrm{bp}$ ) cDNA fragment was ligated into the SmaI site of vector pUC18 and sequenced.

\section{Cloning of the pherophorin cDNA}

A $V$.carteri cDNA library constructed in $\lambda$ gt 11 using poly(A) ${ }^{+}$RNA from sexually induced $(30 \mathrm{~min})$ female spheroids was screened to clone cDNA fragments of pherophorins. The screening and cloning procedures followed standard techniques (Sambrook et al., 1989). DNA sequencing was performed by the chain termination method (Sanger et al., 1977) using T7-DNA polymerase (Pharmacia). Synthetic oligonucleotides were used to sequence the pherophorin cDNAs in both directions.

\section{PCR amplification of pherophorin I and II mRNA}

Ten Volvox spheroids immediately after their release from the mother spheroid were selected under the stereo microscope and transferred into $20 \mu \mathrm{l}$ sterile lysis buffer $(50 \mathrm{mM}$ Tris $-\mathrm{HCl}, \mathrm{pH} 8,300 \mathrm{mM} \mathrm{NaCl}, 5 \mathrm{mM}$ EGTA and 2\% SDS), containing $1 \mu \mathrm{g}$ E.coli 5S RNA as carrier. After $15 \mathrm{~min}$ at $30^{\circ} \mathrm{C}$, Volvox spheroids were removed under the stereo microscope and RNA was precipitated with $60 \mu \mathrm{l}$ ethanol. The washed precipitate (70\% ethanol) was dissolved in $20 \mu \mathrm{l}$ of reverse transcription buffer, containing $50 \mathrm{mM}$ Tris $-\mathrm{HCl}(\mathrm{pH} 8.3), 40 \mathrm{mM} \mathrm{KCl}, 6 \mathrm{mM} \mathrm{MgCl}, 1 \mathrm{mM}$ dithiothreitol, 20 U RNAguard (Pharmacia), $1 \mathrm{mM}$ each dNTP and $50 \mathrm{pmol}$ each antisense primer (ATCGGCCTTAGTAGCGCAGTACCC for pherophorin I, amino acid positions 51-58 and CAGCAGGTTCCAGTTGAGATT for pherophorin II, amino acid positions 429-435). Reverse transcription was initiated with $200 \mathrm{U}$ of MoMuLV reverse transcriptase and continued for $60 \mathrm{~min}$ at $40^{\circ} \mathrm{C}$. $90 \mu \mathrm{l}$ of $1 \times$ PCR buffer containing the sense primers ( $50 \mathrm{pmol}$ each) as well as the antisense primers $(25 \mathrm{pmol}$ each) were added to a $10 \mu \mathrm{l}$ aliquot of the reverse transcription sample. The sense primers used were TAGTGTGTTCATTTGGATAC for pherophorin I, 5'-non-coding sequence and ATGCCGTTCACAGTCTCC for pherophorin II, amino acid positions 336-341). 29 cycles of PCR amplification were performed $\left(94^{\circ} \mathrm{C}, 45 \mathrm{~s} ; 60^{\circ} \mathrm{C}, 30 \mathrm{~s} ; 72^{\circ} \mathrm{C}, 30 \mathrm{~s}\right)$.

\section{Acknowledgements}

We wish to thank Dr R.Deutzmann for sequencing peptides. This work was supported by the Deutsche Forschungsgemeinschaft (SFB 43).

\section{References}

Ertl,H., Mengele,R., Wenzl,S., Engel,J. and Sumper,M. (1989) J. Cell Biol., 109, 3493-3501.

Frohman,M.A., Dush,M.K. and Martin,G.R. (1988) Proc. Natl Acad. Sci. USA, 85, 8998-9002.

Gilles,R., Bittner,C. and Jaenicke,L. (1981) FEBS Lett., 124, 57-61.
Gilles,R., Gilles,C. and Jaenicke,L. (1983) Naturwissenschafien, 70, 571-572.

Gilles,R., Gilles,C. and Jaenicke,L. (1984) Z. Naturforsch., 39c, 584-592. Gilles,R., Moka,R., Gilles,C. and Jaenicke,L. (1985) FEBS Lett., 184, 309-312.

Hager,D.A. and Burgess,R.R. (1980) Anal. Biochem., 109, 76-86.

Kirk,D.L., Birchem,R. and King,N. (1986) J. Cell Sci., 80, 207-231.

Kirk,M.M. and Kirk,D.L. (1985) Cell, 41, 419-428.

Mages,H.-W., Tschochner,H. and Sumper,M. (1988) FEBS Lett., 234, 407-410.

Mort,A.J. and Lamport,D.T.A. (1977) Anal. Biochem., 82, 289- 309.

Provasoli,L., and Pintner,I.J. (1959) In Tyron,C.A. and Hartman,R.T. (eds), The Ecology of Algae. Special Publication No.2. Pymatuning Laboratory of Field Biology, University of Pittsburgh, Pittsburgh, pp. 84-96.

Sambrook J., Fritsch,E.F. and Maniatis,T. (1989) Molecular Cloning: $A$ Laboratory Manual. 2nd edn. Cold Spring Harbor Laboratory Press, Cold Spring Harbor, NY.

Sanger,F., Nicklen,S. and Coulson,A.R. (1977) Proc. Natl Acad. Sci. USA, 74, 5463-5467.

Starr,R.C. (1969) Arch. Protistenk., 111, 204-222.

Starr,R.C. (1970) Dev. Biol., Suppl. 4, 59-100.

Starr,R.C. and Jaenicke,L. (1974) Proc. Natl Acad. Sci. USA, 71, $1050-1054$.

Tschochner,H., Lottspeich,F. and Sumper,M. (1987) EMBO J., 6, 2203-2207.

Wenzl,S. and Sumper,M. (1982) FEBS Lett., 143, 311-315.

Wenzl,S. and Sumper,M. (1986) Dev. Biol., 115, 119-128.

Wenzl,S. and Sumper,M. (1987) In Wiessner, Robinson,D.G. and Starr,R.C. (eds), Algal Development. Springer, Berlin.

Zeikus,J.A. and Starr,R.C. (1980) Arch. Protistenk., 123, 127-161.

Received on November 5, 1992; revised on December 7, 1992

\section{Note added in proof}

The sequence data reported here have been deposited in the EMBL Sequence Data Library under the accession numbers X69801 (pherophorin I) and X69802 (pherophorin II). 